\title{
Investigation of the Microstructures, Mechanical Properties and Corrosion Behaviours of Ti-8Mo-6Ni Alloys Adding NbC Powders via Vacuum Sintering Process
}

\author{
Cheng Liang ${ }^{1,2, a}$, Shih-Hsien Chang ${ }^{2}$, Wei-De Wang ${ }^{2}$, Kuo-Tsung Huang ${ }^{3}$ and Shun-Tian Lin ${ }^{1}$ \\ ${ }^{1}$ Department of Mechanical Engineering, National Taiwan University of Science and Technology, Taipei 10607, \\ Taiwan, ROC \\ ${ }^{2}$ Department of Materials and Mineral Resources Engineering, National Taipei University of Technology, Taipei \\ 10608, Taiwan, ROC \\ ${ }^{3}$ Department of Auto-Mechanics, National Kangshan Agricultural Industrial Senior High School, Kaohsiung 82049 , \\ Taiwan, ROC
}

\begin{abstract}
In this study, the Ti-8Mo-6Ni alloys are subjected to add various amounts of $\mathrm{NbC}$ carbides as a strengthening phase after the sintering process. Meanwhile, the composite materials underwent a vacuum sintering process at different temperatures of $1175^{\circ} \mathrm{C}, 1225^{\circ} \mathrm{C}$ and $1275^{\circ} \mathrm{C}$ for $1 \mathrm{~h}$, respectively. To evaluate the microstructure, mechanical properties and corrosion behaviors of the Ti-8Mo-6 $\mathrm{Ni}$ alloys adding $\mathrm{NbC}$ via the vacuum sintering processes, tests on the relative density, hardness, transverse rupture strength (TRS), corrosion and microstructure inspections are performed using XRD and SEM, with the aim of improving the microstructure and properties of sintered Ti-8Mo-6Ni alloys. The experimental results showed that when $1 \mathrm{wt} \%$ of $\mathrm{NbC}$ carbides is added to the Ti-8Mo-6 $\mathrm{Ni}$ alloys they possessed the optimal properties after sintering at $1275^{\circ} \mathrm{C}$ for $1 \mathrm{~h}$. The sintering density increased to about $99.7 \%$, the hardness is enhanced to $48.1 \mathrm{HRC}$ and the TRS increased to $976 \mathrm{MPa}$. Meanwhile, the sintered composite materials possessed good corrosion resistance.
\end{abstract}

\section{Introduction}

During the past few decades, $\beta$ titanium alloys have become one of the most promising candidates due to their high specific strength and good corrosion resistance [1, 2]. Mo is desirable as an alloying element for the development of Ti-based biomaterials. Previous researches have studied the phase transformations and mechanical properties of different Ti-Mo alloys, and found that the phase constitutions, elastic modulus and hardness are different for Ti-Mo alloys with different Mo contents $[3,4]$. It is remarkable that the Ti-8Mo exhibits the highest mechanical properties among the porous Ti-(4-10 wt\%)Mo alloys [2, 5]. Powder metallurgy (P/M) methods offer various types of materials with the objective of achieving higher strength, hardness and wear resistance for composite materials such as titanium-based alloys powders. Conventional $\mathrm{P} / \mathrm{M}$ involves mixing the metal powders, compacting of the mixed powders into moulds and then sintering of the compact powders under the different atmospheres $[6,7]$. Furthermore, our previous study has shown that the combination of these

\footnotetext{
${ }^{\mathrm{a}}$ Corresponding author: 1cheng@ntut.edu.tw
} 
elements in a Ti-8Mo-6Ni alloy has a good balance between mechanical properties and hot workability [2].

The niobium carbide $(\mathrm{NbC})$ possesses a high melting point $\left(3600^{\circ} \mathrm{C}\right)$ and hardness $(\mathrm{HV} 2800)$. It is known to inhibit grain growth in high temperature of PM process $[8,9]$. Moreover, the wettability with binder of $\mathrm{NbC}$ is much better than the other carbides. In recent years, attention of many researchers was taken on $\mathrm{NbC}$ for its attractive properties. On the other hand, the previous literature also indicated that the addition of $\mathrm{NbC}$ substantially refined the structure and improved the mechanical properties of alloy materials [10]. The present research selected the Ti-8Mo-6Ni alloy and added the different amounts of $\mathrm{NbC}$ carbides as a strengthening phase. The effects of the microstructural evolution on the mechanical and corrosion properties of $\mathrm{NbC}$ carbides added to Ti$8 \mathrm{Mo}-6 \mathrm{Ni}$ alloys through the vacuum sintering process at various temperatures were determined.

\section{Experimental Procedures}

In the research, different amounts of $\mathrm{NbC}$ powders $(1,3$ and $5 \mathrm{wt} \%)$ were added to Ti-8Mo-6Ni alloy powders. Meanwhile, the Ti-8Mo-6Ni powder samples with the various added amounts of $\mathrm{NbC}$ powder were denoted as $\mathrm{NbC}-1, \mathrm{NbC}-3$ and $\mathrm{NbC}-5$, respectively. In this study, the PVA (polyvinyl alcohol) as a binder was added. The green body $\left(40 \times 6 \times 8 \mathrm{~mm}^{3}\right)$ of the powder specimen was produced under a uniaxial pressure at $40 \mathrm{MPa}$ for $300 \mathrm{sec}$. The vacuum sintering was conducted at 1175,1225 and $1275^{\circ} \mathrm{C}$ for $1 \mathrm{~h}$ in a $1.3 \times 10^{-3} \mathrm{~Pa}$, respectively. A Microtrac X 100 laser was used to analyze the particle size of the refined $\mathrm{Ti}$, Mo and Ni powders. The mean particle sizes of the reduced $\mathrm{Ti}$, Mo and Ni powders were about $28.4 \pm 0.3,12.4 \pm 0.5$ and $9.9 \pm 0.7 \mu \mathrm{m}$, respectively. Moreover, the $\mathrm{NbC}$ powder was $6.353 \pm 0.215 \mu \mathrm{m}$.

To evaluate the effects of $\mathrm{NbC}$ strengthening phase on the Ti-8Mo-6Ni alloys via vacuum sintering process, this study conducted volume shrinkage rate, relative density, hardness, Transverse Rupture Strength (TRS) tests, X-ray diffraction (XRD) and Scanning Electron Microscopy (SEM) microstructure observations. The Hung Ta universal material test machine (HT-9501A) with a maximum load of $245 \mathrm{kN}$ was used for the TRS tests (ASTM B528-05). Simultaneously, $\mathrm{R}_{\mathrm{bm}}$ was the TRS, which is determined as the fracture stress in the surface zone. F was maximum fracture load, $\mathrm{L}$ was $30 \mathrm{~mm}$, $\mathrm{k}$ was chamfer correction factor (normally 1.00-1.02), b and h were $5 \mathrm{~mm}$ in the equation $\mathrm{R}_{\mathrm{bm}}=3 F L k / 2 b h^{2}$, respectively. The specimen dimensions of the TRS test were $5 \times 5 \times 40 \mathrm{~mm}^{3}$. Porosity test was conducted in accordance to the ASTM C373-88 standard. Hardness tests were measured by HRC with a loading of $1.47 \mathrm{kN}$, which followed the ASTM E18-3 standard.

Furthermore, corrosion potential analysis uses three electrodes method and follows by ASTM G59-97: the reference electrode is a saturated of silver-silver chloride electrode, auxiliary electrode uses a platinum electrode, and the working electrode is connected to the test specimens. The contact area of the specimen was $0.785 \mathrm{~cm}^{2}$. The corrosive solvent used $3.5 \mathrm{wt} \% \mathrm{NaCl}$ was maintained at room temperature. A scanning speed of $0.01 \mathrm{Vs}^{-1}$, initial potential of $-2.0 \mathrm{~V}$, and the final potential of $2.0 \mathrm{~V}$ were controlled [7]. The polarization curve was obtained by Corr-View software to analyze and compare the corrosion potential $\left(\mathrm{E}_{\text {corr }}\right)$, corrosion current $\left(\mathrm{I}_{\text {corr }}\right)$ and polarization resistance $\left(\mathrm{R}_{\mathrm{p}}\right)$ of $\mathrm{NbC}-1, \mathrm{NbC}-3$ and NbC-5 sintered specimens.

\section{Results and Discussion}

Fig. 1 shows the volume shrinkage and relative density of the $\mathrm{NbC}-1, \mathrm{NbC}-3$ and $\mathrm{NbC}-5$ specimens through the different sintering temperatures. The volume shrinkage rate of the $\mathrm{NbC}-1, \mathrm{NbC}-3$ and $\mathrm{NbC}-5$ specimens significantly increased as the sintering temperature increased, as shown in Fig. 1a. As a result, the $\mathrm{NbC}-1, \mathrm{NbC}-3$ and $\mathrm{NbC}-5$ specimens possessed a higher volume shrinkage rate after sintering at $1275^{\circ} \mathrm{C}$ for $1 \mathrm{~h}$. The highest volume shrinkage rate was $32.9 \pm 1.0,33.1 \pm 0.5$ and $34.1 \pm 0.6 \%$, which appeared in the $\mathrm{NbC}-1, \mathrm{NbC}-3$ and $\mathrm{NbC}-5$ specimens after $1275^{\circ} \mathrm{C}$ sintering for $1 \mathrm{~h}$, respectively. It was reasonable to suggest that the $\mathrm{NbC}$ powder added to Ti-8Mo-6Ni alloys 
effectively filled the voids during the sintering process, which led to the small pores in the specimens decreasing, since the higher temperature sintering enhanced the volume shrinkage rate.

In addition, the $\mathrm{NbC}-1, \mathrm{NbC}-3$ and $\mathrm{NbC}-5$ specimens had a higher relative density after sintering at $1275^{\circ} \mathrm{C}$ for $1 \mathrm{~h}$, as shown in Fig. $1 \mathrm{~b}$. The suitable amount of $\mathrm{NbC}$ powder in the Ti-8Mo-6Ni specimens advantageous to the relative density resulted from the increase in the diffusion rate at higher sintering temperatures. Through increasing the added amount of $\mathrm{NbC}$ powders and the sintering temperature $\left(1275^{\circ} \mathrm{C}\right)$, the near-full density of the Ti-8Mo-6Ni alloy could be acquired. Consequently, the highest relative density was $99.7 \pm 0.14,99.6 \pm 0.21$ and $99.6 \pm 0.03 \%$, which appeared in the $\mathrm{NbC}-1, \mathrm{NbC}-3$ and $\mathrm{NbC}-5$ specimens after $1275^{\circ} \mathrm{C}$ sintering for $1 \mathrm{~h}$, respectively. Clearly, the optimal sintering temperature of Ti-8Mo-6 Ni alloy adding $\mathrm{NbC}$ powders was $1275^{\circ} \mathrm{C}$.

Fig 2 reveals the XRD patterns of the $\mathrm{NbC}-1, \mathrm{NbC}-3$ and $\mathrm{NbC}-5$ specimens after sintering at $1275^{\circ} \mathrm{C}$ for $1 \mathrm{~h}$. Previous study indicated that the impurity concentrations of vacuum-sintered commercially pure titanium with fine grains were sufficiently low to meet the ASTM standard. It illustrates that the oxygen, nitrogen and hydrogen contents of the specimens was lower than that of ASTM (B381-10) [2, 11]. As a result, the contamination levels such as oxygen, nitrogen and hydrogen can be ignored. In this work, the XRD patterns also confirm that there are no other oxide appeared in the specimens, as show in Fig. 2. Significantly, $\alpha, \beta$ titanium and TiC peaks appeared in the XRD patterns of the $\mathrm{NbC}-1, \mathrm{NbC}-3$ and $\mathrm{NbC}-5$ specimens after sintering at $1275^{\circ} \mathrm{C}$ for $1 \mathrm{~h}$. There were no any $\mathrm{NbC}$ peaks generated after vacuum sintering process. The experimental results confirmed to our previous study, the oversaturated $\mathrm{Ni}$ which precipitated as TiNi intermetallic compounds coexisted with $\beta$ titanium; moreover, $\alpha$ titanium precipitated plate-like at the grain boundaries of the $\beta$ matrix. At the same time, the $\mathrm{NbC}$ and $\mathrm{Ti}$ reaction and transform to $\mathrm{TiC}$ after sintering process.

(a)

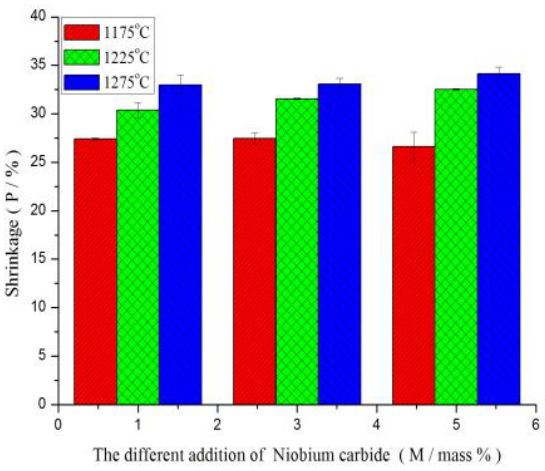

(b)

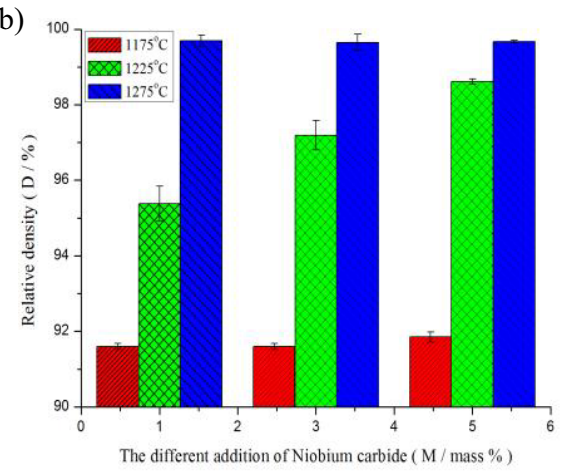

Figure 1. Comparison of the shrinkage and relative density of $\mathrm{NbC}-1, \mathrm{NbC}-3$ and $\mathrm{NbC}-5$ specimens after various sintering temperatures

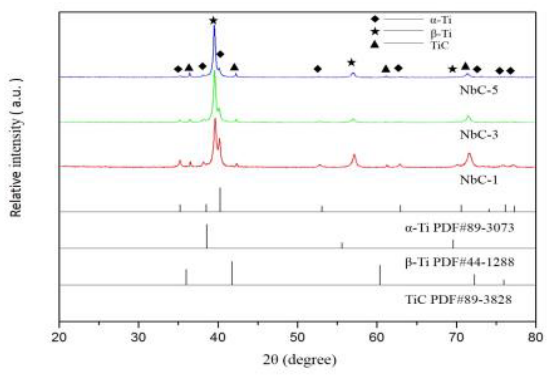

Figure 2. XRD patterns of the $\mathrm{NbC}-1, \mathrm{NbC}-3$ and $\mathrm{NbC}-5$ specimens after sintering at $1275^{\circ} \mathrm{C}$ for $1 \mathrm{~h}$. $\alpha$ titanium precipitated at the grain boundaries of the $\beta$ matrix, the $\mathrm{NbC}$ and Ti react and transform into TiC plus eutectoid $\beta$ $\mathrm{Ti}(\mathrm{Nb})_{\mathrm{x}}$ phase after sintering process. 
On the other hand, the SEM morphology observations of $\mathrm{NbC}-1, \mathrm{NbC}-3$ and $\mathrm{NbC}-5$ specimens by vacuum sintering at $1275^{\circ} \mathrm{C}$ for $1 \mathrm{~h}$, as shown in Fig. 3. The porosity significantly decreased after the high-temperature sintering. Moreover, the grain size was obviously decreased as the $\mathrm{NbC}$ increased. Among them, the compositions and amounts of the elements of the $\mathrm{NbC}-1$ specimen were determined. A high magnified SEM image is shown in Fig. 4a. Meanwhile, the circular precipitates (black) were TiC (point 1), and EDS analysis as shown in Fig. 4b. The threadlike precipitates (white) were $\beta$ titanium (point 2) which randomly dispersed within the grains, and EDS analysis as shown in Fig. 4c. Notably, $\alpha$ titanium distributed in the precipitates surrounded. Furthermore, location of the 3 was $\beta$ titanium (point 3), and EDS analysis as shown in Fig. $4 d$. These results confirmed that the $\mathrm{NbC}-1$ specimen formed $\alpha+\beta$ titanium alloys and $\mathrm{TiC}$ carbides. The results agree with the XRD finding.
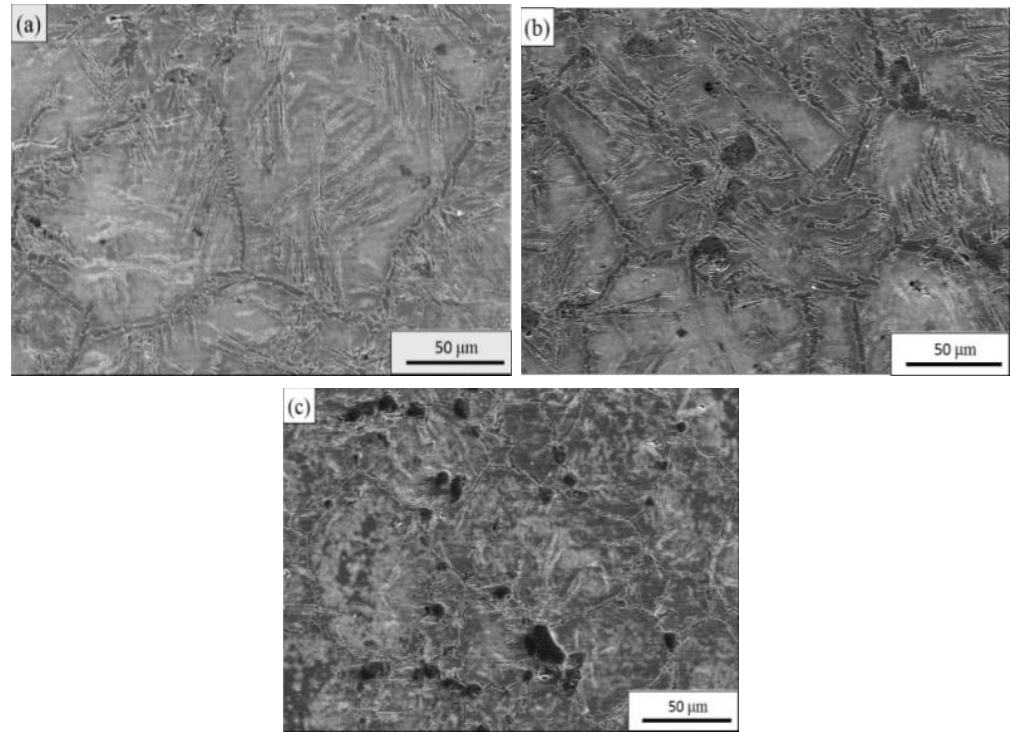

Figure 3. Comparison of SEM morphology observations of (a) NbC-1, (b) NbC-3 and (c) NbC-5 specimens by vacuum sintering at $1275^{\circ} \mathrm{C}$ for $1 \mathrm{~h}$.
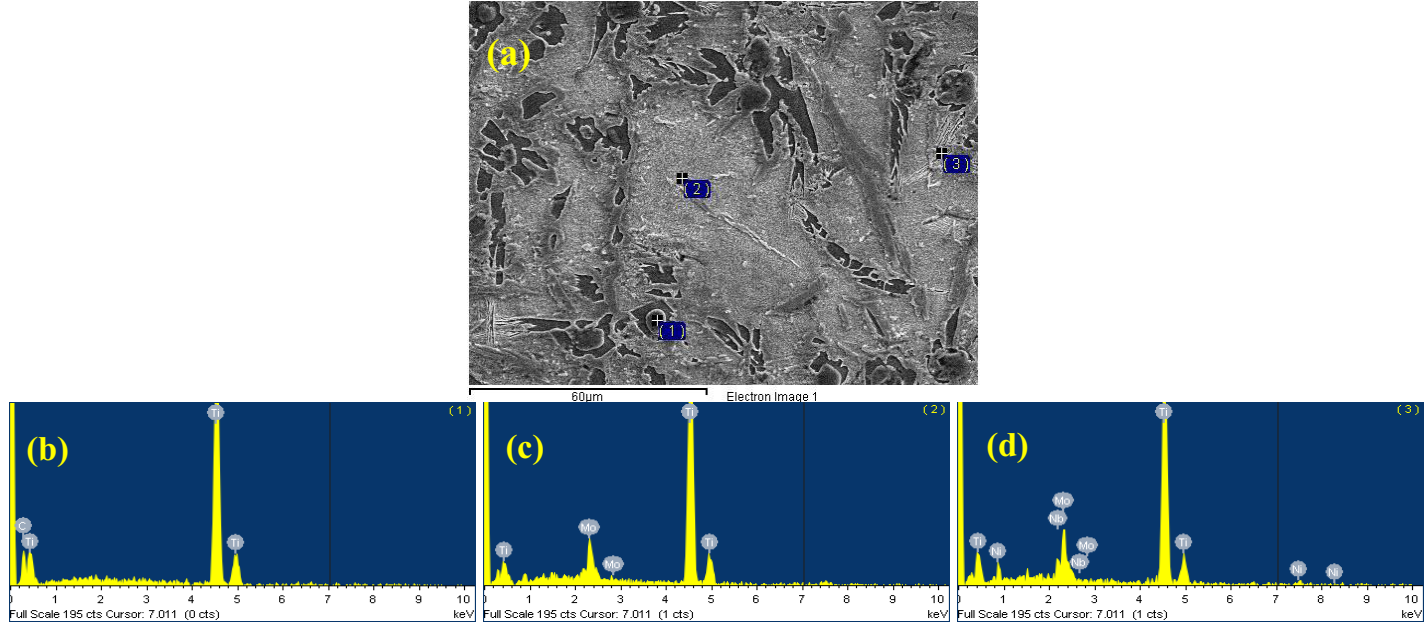

Figure 4. EDS analysis of NbC-1 specimen by vacuum sintering at $1275^{\circ} \mathrm{C}$ (a) a high magnified SEM image, (b) location 1, (c) location 2, and (d) location 3. 
Fig. 5 shows the mechanical properties of $\mathrm{NbC}-1, \mathrm{NbC}-3$ and $\mathrm{NbC}-5$ specimens by vacuum sintering at different temperatures. The hardness of the Ti-8Mo-6 Ni specimens improved as the sintering temperature increased, and it was dramatically improved as the added amount of $\mathrm{NbC}$ powders increased, as shown in Fig. 5a. The previous literature indicates that decreasing the porosities and increasing the density of sintered materials effectively enhances plastic deformation resistance and hardness $[2,12]$. In this study, the porosities decreased and the relative density increased as the sintering temperature was raised $\left(1175 \rightarrow 1225 \rightarrow 1275^{\circ} \mathrm{C}\right)$, which could be the main factor in improving hardness. Besides, the TiNi intermetallic compounds belong to the hard and brittle materials uniformly distributed in the $\beta$ matrix, which could be another factor in improving the hardness. As a result, the higher hardness appeared in the $\mathrm{NbC}-1$ specimens, and the highest hardness value of HRC $48.1 \pm 0.7$ appeared after sintering at $1275^{\circ} \mathrm{C}$ for $1 \mathrm{~h}$. This could be ascribed to the higher relative density $(99.7 \%)$, dispersion-strengthened TiNi compounds and $\mathrm{MC}$ carbides.

Fig. $5 b$ shows the TRS values of the $\mathrm{NbC}-1, \mathrm{NbC}-3$ and $\mathrm{NbC}-5$ specimens after sintering at various temperatures. Notably, the TRS values of the Ti-8Mo-6Ni specimens significantly decreased as the added amount of $\mathrm{NbC}$ powders increased after sintering at $1275^{\circ} \mathrm{C}$ for $1 \mathrm{~h}$, and when the added amount of $\mathrm{NbC}$ powders increased to $5 \%$, the TRS value obviously decreased $(645 \pm 36 \mathrm{MPa})$. The highest TRS value of $976 \pm 23 \mathrm{MPa}$ appeared in the $\mathrm{NbC}-1$ specimens after sintering at $1275^{\circ} \mathrm{C}$ for $1 \mathrm{~h}$. Previous study $[2,13]$ has indicated that the needle-like microstructure of the Widmanstätten-like structure leads to brittle behavior of the carbon steels. However, it is good for the ductility of the Ti alloys. It is reasonable to speculate that the more Widmanstätten-like structure uniformly distributed in the Ti-8Mo-6Ni specimens after sintering at $1275^{\circ} \mathrm{C}$ for $1 \mathrm{~h}$. In this study, the amount of Widmanstätten-like structure increase is effective in improving the TRS values. In addition, the excessive precipitation of TiNi intermetallic compounds and $\mathrm{MC}$ carbides within the $\beta$ matrix and the grain coarsening appeared as the added amount of $\mathrm{NbC}$ powders increased, which were disadvantageous to the TRS. Consequently, added suitable amount of NbC powders to Ti-8Mo-6Ni alloys was effectively improved the mechanical properties after vacuum sintering process.

(a)

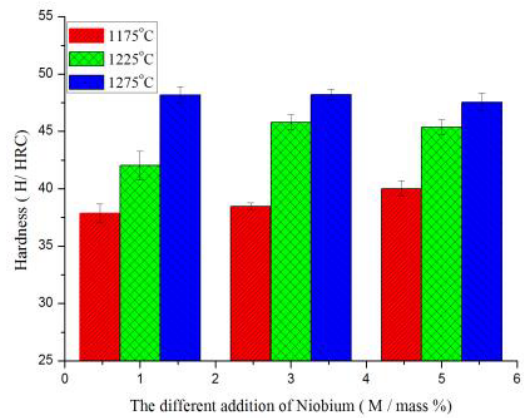

(b)

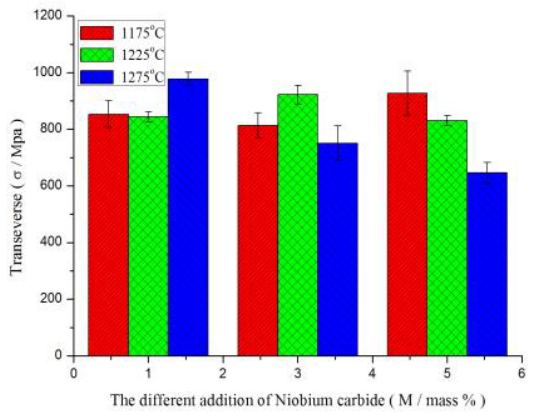

Figure 5. Comparison of the mechanical properties of $\mathrm{NbC}-1, \mathrm{NbC}-3$ and $\mathrm{NbC}-5$ specimens by vacuum sintering at different temperatures (a) hardness, and (b) TRS test result.

Fig. 6 shows the Tafel results of $\mathrm{NbC}-1, \mathrm{NbC}-3$ and $\mathrm{NbC}-5$ specimens by vacuum sintering at $1275^{\circ} \mathrm{C}$ for $1 \mathrm{~h}$ after $3.5 \mathrm{wt} \% \mathrm{NaCl}$ corrosion test. All the sintered specimens possessed a significant passivation phenomenon after the $3.5 \mathrm{wt} \% \mathrm{NaCl}$ corrosion test. Generally speaking, in an electrochemical reaction, the current value represents the diversification of the equilibrium constants in the oxidation reaction. If the current value is higher, it leads to an increase in the equilibrium constant and a fast corrosion rate. However, the polarization resistance must also be considered. Higher polarization resistance usually means better corrosion resistance. In the research, the lowest $\mathrm{I}_{\text {corr }}\left(3.21 \times 10^{-7} \mathrm{~A} \cdot \mathrm{cm}^{-2}\right)$ and highest $\mathrm{R}_{\mathrm{p}}\left(29172 \Omega \cdot \mathrm{cm}^{2}\right)$ appeared in the NbC-3 specimens after sintering at $1275^{\circ} \mathrm{C}$ for $1 \mathrm{~h}$, which effectively improved the corrosion resistance. Furthermore, the NbC-1 specimens also possessed the lower $I_{\text {corr }}\left(2.88 \times 10^{-6} \mathrm{~A} \cdot \mathrm{cm}^{-2}\right)$ and higher $\mathrm{R}_{\mathrm{p}}\left(24768 \Omega \cdot \mathrm{cm}^{2}\right)$ after sintering at $1275^{\circ} \mathrm{C}$ for $1 \mathrm{~h}$. The result can be further compared with the relative density as shown in 
Fig. 1b, it is reasonable to suggest that the electrochemical characteristics are principally controlled by porous features. This could be ascribed to the latter's higher porosity, which resulted from a few pores around the $\mathrm{NbC}$ particles. According to the above discussion and results, it was speculated that the $\mathrm{NbC}-1$ specimens sintered at $1275^{\circ} \mathrm{C}$ for $1 \mathrm{~h}$ possessed the optimal hardness and TRS and better corrosion resistance, which result from the more amount and uniform distribution of Widmanstättenlike structure and higher relative density.

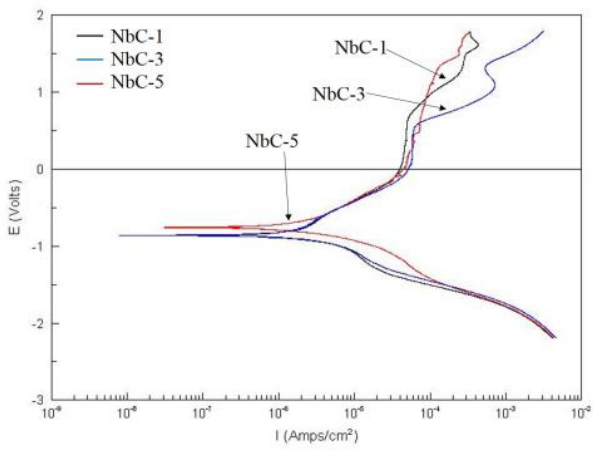

Figure 6. Tafel results of NbC-1, NbC-3 and NbC-5 specimens by vacuum sintering at $1275^{\circ} \mathrm{C}$ for $1 \mathrm{~h}$ after 3.5 $\mathrm{wt} \% \mathrm{NaCl}$ corrosion test.

\section{Conclusions}

In this work, a highest sintering density (99.7\%) and hardness (48.1 HRC) of the NbC-1 specimens were acquired after sintering at $1275^{\circ} \mathrm{C}$ for $1 \mathrm{~h}$. Meanwhile, the $\mathrm{NbC}-1$ specimens also possessed a highest TRS value (976 MPa). Significantly, the suitably ( $1 \mathrm{wt} \% \mathrm{NbC}$ ) and uniformly distributed TiNi intermetallic compounds within the $\beta$ matrix were advantageous to the TRS. On the other hand, the lowest $\mathrm{I}_{\text {corr }}\left(3.21 \times 10^{-7} \mathrm{~A} \cdot \mathrm{cm}^{-2}\right)$ and highest $\mathrm{R}_{\mathrm{p}}\left(29172 \Omega \cdot \mathrm{cm}^{2}\right)$ appeared in the NbC-3 specimens after sintering at $1275^{\circ} \mathrm{C}$ for $1 \mathrm{~h}$, which effectively improved the corrosion resistance.

\section{Acknowledgments}

The research is supported by the ASSAB STEELS TAIWAN CO., LTD. The authors would like to express their appreciations for Dr. Harvard Chen and Michael Liao.

\section{References}

1. H. Matsumoto, S. Watanabe, S. Hanada, J. Alloy. Compd. 439, 146 (2007)

2. C. Liang, S.H. Chang, W.D. Wang, K.T. Huang, S.T. Lin, Mater. Trans. 57, 1363 (2016)

3. W.D. Zhang, Y. Liu, H. Wu, M. Song, T.Y. Zhang, X.D. Lan, T.H. Yao, Mater. Charact. 106, $302(2015)$

4. S.H. Chang, P.Y. Chang, Mater. Sci. Eng. A. 606, 150 (2014)

5. F.X. Xie, X.M. He, Y.M. Lv, M.P. Wu, X.B. He, X.H. Qu, Corr. Sci. 95, 117 (2015)

6. S.H. Chang, J.C. Chen and K.T. Huang, J.K. Chen, Mater. Trans. 54, 1034 (2013)

7. S.H. Chang, S.L. Chen, J. Alloy. Compd. 585, 407 (2014)

8. J. Weidow, H.O. Andrén, Int. J. Refract. Met. H. 29, 38 (2011)

9. T.B. Trung, H. Zuhailawati, Z.A. Ahmad, K.N. Ishihara, J. Alloy. Compd. 552, 20 (2013)

10. W. Zhou, J. Xiong, W.C. Wan, Z.X. Guo, Z.H. Lin, S.W. Huang, L.M. Tang, H. Zhong, Int. J. Refract. Met. H. 50, 72 (2015)

11. P. Sun, Z.Z. Fang, M. Koopman, Adv. Eng. Mater. 15, 1007 (2012)

12. C. Liang, S.H. Chang, J.R. Huang, K.T. Huang, S.T. Lin, Mater. Trans. 56, 1127 (2015)

13. H. Fujii, Nippon steel technical report. 62, 74 (1994) 